\title{
ESTUDO DA EROSÃO NA MICROBACIA DO CEVEIRO (PIRACICABA, SP). I - ESTIMATIVA DAS TAXAS DE PERDA DE SOLO E ESTUDO DE SENSIBILIDADE DOS FATORES DO MODELO EUPS ${ }^{(1)}$
}

\author{
Mara de Andrade Marinho Weill ${ }^{(2)} \&$ Gerd Sparovek $^{(3)}$
}

\begin{abstract}
RESUMO
A erosão acelerada do solo constitui um sério problema global de degradação de terras agrícolas. Por ser a pesquisa de erosão comumente cara e morosa, a utilização de modelos permite estimar a perda de solo em localidades e condições não diretamente representadas nos estudos. $O$ objetivo deste trabalho foi estimar a expectativa de erosão do solo em uma área intensivamente cultivada com canade-açúcar no município de Piracicaba (SP), como subsídio ao diagnóstico do uso atual das terras visando ao controle do processo. O trabalho foi realizado em ambiente de sistema de informação geográfica aplicando a equação universal de perda de solo (EUPS). Especificamente pretendeu-se estudar a influência dos fatores K (erodibilidade do solo), LS (topográfico), C (uso e manejo da cultura) e P (práticas de controle da erosão) nas estimativas de perda de solo. Os resultados obtidos mostraram que o processo de degradação dos solos por erosão acelerada é intenso em cerca de dois terços da área avaliada, ocupados principalmente com cana-de-açúcar. Nessas áreas, a perda média estimada de $58 \mathrm{Mg} \mathrm{ha}^{-1}$ ano $^{-1}$ equivale a cerca de quatro vezes o limite superior da tolerância média indicada. Nas áreas remanescentes, ocupadas com mata, vegetação ciliar, reflorestamento e pastagens, as taxas estimadas de perda de solo são baixas, em torno de $2 \mathrm{Mg} \mathrm{ha}^{-1} \mathrm{ano}^{-1}$, abaixo dos valores de tolerância. $\mathrm{O}$ estudo de sensibilidade dos fatores do modelo revelou que, para uma mesma condição climática (fator $R$ constante), os fatores $\mathbf{C}$ e $P$ (cobertura e manejo da cultura e práticas de controle da erosão) definiram a ordem
\end{abstract}

\footnotetext{
(1) Parte da Tese de Doutorado do primeiro autor, com bolsa do CNPq. Trabalho realizado com auxílio financeiro da Fundação de Amparo à Pesquisa do Estado de São Paulo - FAPESP. Trabalho apresentado no XXIX Congresso Brasileiro de Ciência do Solo, Ribeirão Preto, 2003. Recebido para publicação em janeiro de 2006 e aprovado em novembro de 2007.

(2) Professora Doutora da Faculdade de Engenharia Agrícola da Universidade de Campinas - FEAGRI/UNICAMP. Cidade Universitária Zeferino Vaz, Caixa Postal 6011, CEP 13083-875 Campinas (SP). E-mail: mweill@agr.unicamp.br

${ }^{(3)}$ Professor Associado do Departamento de Solos e Nutrição de Plantas da Escola Superior de Agricultura "Luiz de Queiroz" ESALQ. Caixa Postal 09, Av. Pádua Dias 11, CEP 13418-900 Piracicaba (SP). E-mail: gerd@esalq.usp.br
} 
de grandeza das perdas, em unidades, dezenas ou centenas de $\mathrm{Mg} \mathrm{ha}^{-1} \mathrm{ano}^{-1}$. Para uma mesma categoria de uso da terra (fatores $\mathrm{C}$ e $\mathrm{P}$ constantes), o fator LS foi o que explicou a maior parte da variação observada. Os resultados obtidos a partir de uma simulação mostraram que a influência do fator K (erodibilidade do solo) nas estimativas foi muito menor do que a do fator topográfico. A aplicação da EUPS permitiu estimar a expectativa de erosão do solo na área de estudo. $O$ uso de geotecnologias e de métodos geoestatísticos de análise mostrou-se uma abordagem promissora nos estudos de erosão.

Termos de indexação: Córrego do Ceveiro, Equação Universal de Perda de Solo, sistema de informação geográfica, programa IDRISI, cana-de-açúcar.

\title{
SUMMARY: EROSION STUDY IN THE CEVEIRO WATERSHED (PIRACICABA, SP). I - ESTIMATION O SOIL LOSS RATES AND SENSITIVITY FACTOR ANALYSIS OF THE USLE MODEL
}

\begin{abstract}
Accelerated soil erosion is a serious global problem that degrades agriculture lands. Since erosion research is normally expensive and time-consuming, the use of models allows to estimate soil losses at locations and under conditions not represented directly in the research. The objective of this study was to estimate the soil erosion in an area intensively cultivated with sugarcane near the city of Piracicaba, São Paulo, contributing to diagnose the current land uses aimed at controlling erosion. The study was carried out based on a geographic information system using the universal soil loss equation (USLE) to estimate erosion. A specific objective of the study was to analyze the influence of $K$ (soil erodibility), $L S$ (topography), $C$ (crop use and management) and $P$ (erosion control practices) factors in soil loss estimates. The results show an intense soil degradation process by accelerated erosion in nearly two-thirds of the studied area, mainly occupied by sugarcane. In these areas, the average estimated soil loss rate of $58 \mathrm{Mg} \mathrm{ha}^{-1}$ year-1 is equivalent to nearly four times the indicated average upper tolerance limit. In the remaining areas occupied by forest, riparian vegetation, afforestation and pasture, the estimated soil loss rates are low, around $2 \mathrm{Mg} \mathrm{ha}^{-1}$ year-1, below the tolerance values. The model factor sensitivity analysis revealed that under the same weather condition (constant $R$ factor), factors $C$ and $P$ (crop management and coverage and erosion control practices) defined the magnitude of the soil losses, whether in units, tens or hundreds of $M g \mathrm{ha}^{-1}$ year ${ }^{-1}$. For a same category of land use (factors $C$ and $P$ constant), the LS factor (topographic) explained most of the observed variation. The results obtained from a simulation showed that the estimates were much less influenced by the $K$ (soil erodibility) than by the topographic factor. The application of USLE permitted an estimation of expected soil erosion in the study area. The use of geotechnological and geostatistical analysis methods seems to be a promising approach in erosion studies.
\end{abstract}

Index terms: Ceveiro stream, geographic information system, IDRISI software, sugarcane, Universal Soil Loss Equation.

\section{INTRODUÇÃO}

A erosão acelerada do solo constitui um sério problema global de degradação de terras e um dos maiores riscos ambientais da atualidade (Lal \& Stewart, 1990). Nos trópicos úmidos, as conseqüências da erosão acelerada são ainda mais sérias do que em outras regiões (El-Swaif \& Dangler, 1982). No Brasil, dados apresentados por Bertoni \& Lombardi Neto (1999), com base em estimativas efetuadas por Marques (1949), sugerem uma perda anual de solo por erosão de cerca de 500 milhões de toneladas.
Segundo os autores, o estado de São Paulo responde por cerca de $25 \%$ da perda nacional, decorrente de uso intensivo ou indevido das terras. Castro (1991) indica perdas maiores: 200 milhões de toneladas por ano.

No planejamento do uso das terras em bases sustentáveis, a caracterização da extensão, a magnitude e as taxas atuais da erosão é uma etapa importante do diagnóstico (Schertz, 1983). A pesquisa de erosão é cara e morosa (Lal, 1994) por envolver a avaliação de inúmeras combinações possíveis entre diferentes tipos de terras e alternativas de uso e 
manejo. A utilização de modelos nesse caso é fundamental, uma vez que as equações de perda de solo habilitam o planejador a projetar dados experimentais de erosão para localidades e condições não diretamente representadas nas pesquisas (Wischmeier \& Smith, 1978). Há modelos complexos, inclusive determinísticos, para estimar a erosão (Mc Cool \& Renard, 1990; Rose, 1997), mas que requerem um grande número de informações. Na ausência ou escassez dos dados necessários, a aplicação dos modelos se torna pouco confiável (Bouma, 1989). Por sua simplicidade, por ser bastante conhecida e estudada e por requerer um número relativamente pequeno de informações, a equação universal de perda de solo (Wischmeier \& Smith, 1978) é muito utilizada na predição das perdas de solo por erosão entressulcos e em sulcos pequenos.

Considerando a erosão acelerada do solo um grande fator de degradação das terras mais intensivamente cultivadas no estado de São Paulo e a necessidade de constante evolução metodológica, procedeu-se a um estudo de caso no município de Piracicaba (SP), combinando modelagem de perda de solo e geotecnologias. Os objetivos foram estimar as taxas médias anuais de perda de solo e analisar a influência da variação local dos fatores do modelo na variação observada das taxas de erosão, como subsídios ao diagnóstico do uso da terra em uma área intensivamente cultivada com cana-de-açúcar. A escolha da área se deveu ao fato de o manejo aplicado reproduzir a condição média de produção da cultura da cana-de-açúcar na região de Piracicaba.

\section{MATERIAL E MÉTODOS}

\section{A microbacia do ceveiro}

A área de estudo compreende quase a totalidade da microbacia do córrego do Ceveiro, pertencente à bacia do Rio Piracicaba (Piracicaba, SP), com aproximadamente 1.990 ha (Figura 1 ). O clima, pela classificação de Köppen, é mesotérmico de inverno seco (Cwa), com temperatura média anual de $21,5{ }^{\circ} \mathrm{C}$ e precipitação média anual de $1.257 \mathrm{~mm}$. O relevo local é suave ondulado, com cotas variando entre 460 e $580 \mathrm{~m}$. A declividade predominante nas encostas varia na faixa entre $0,05 \mathrm{~m} \mathrm{~m}^{-1} \mathrm{e} 0,15 \mathrm{~m} \mathrm{~m}^{-1}$, sendo inferior a $0,05 \mathrm{~m} \mathrm{~m}^{-1}$ nos topos.

A cultura da cana-de-açúcar é o uso principal, ocorrendo em 1.319 ha $(66 \%)$, de acordo com levantamento elaborado por Fiorio (1998) (Figura 2). Seguem-se usos menos intensivos com pastagens (278 ha), reflorestamento (121 ha), matas e vegetação ciliar (225 ha), que em conjunto perfazem outros 624 ha (26\% da área). O uso com culturas anuais é de menos de $1 \%$ da área (3 ha). Ocorrem ainda 39 ha de áreas urbanas (2\%), correspondentes ao distrito de Ártemis (a jusante) e à vila de Santana (a montante), e três corpos d'água, incluindo uma barragem de acumulação, que totalizam 5,5 ha $(0,3 \%)$.

$\mathrm{Na}$ área de estudo, o embasamento geológico é constituído por arenitos finos a médios, avermelhados, sílticos-argilosos da Formação Pirambóia, por

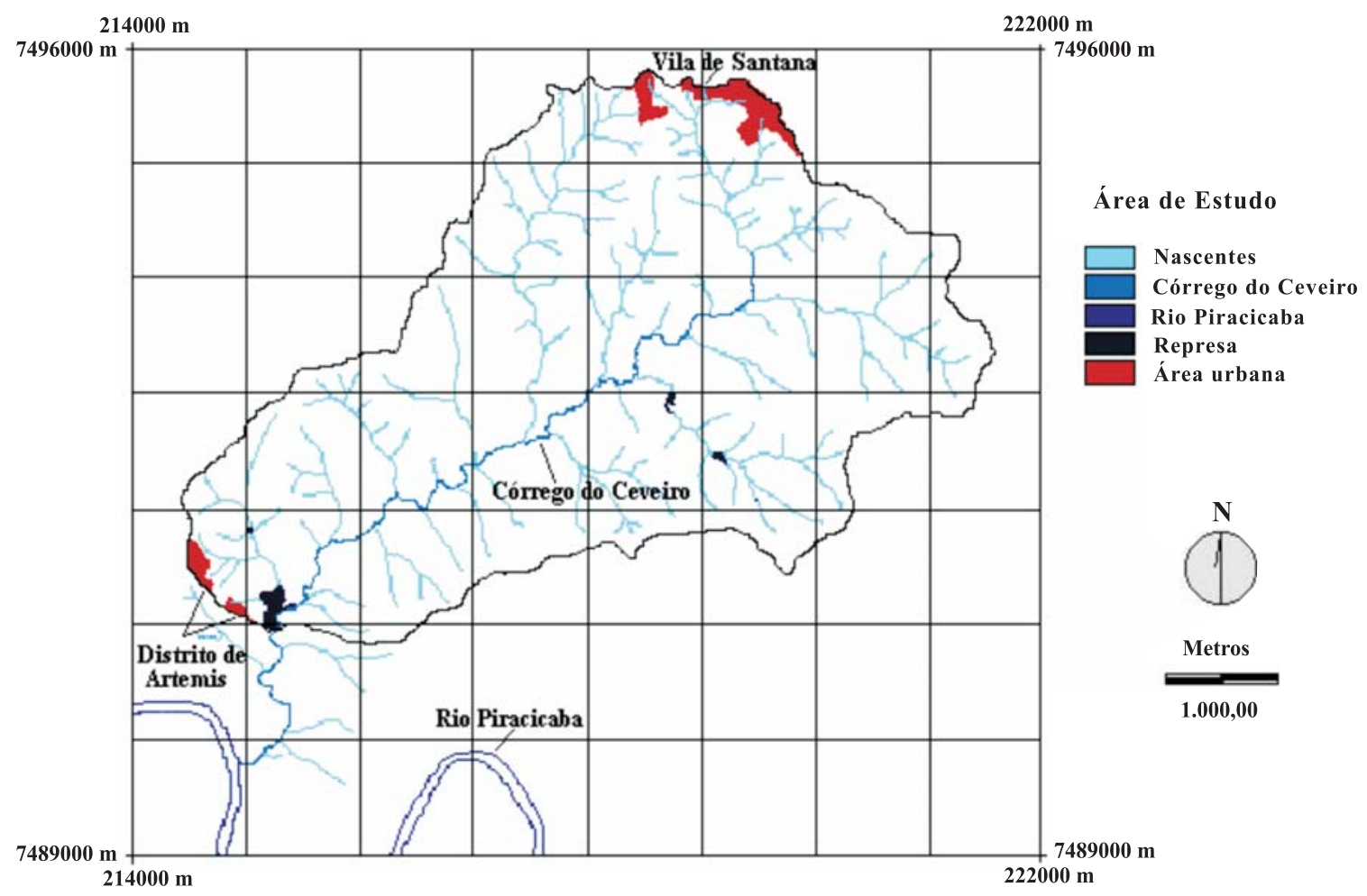

Figura 1. Área de estudo: limites, área urbana e hidrografia. 


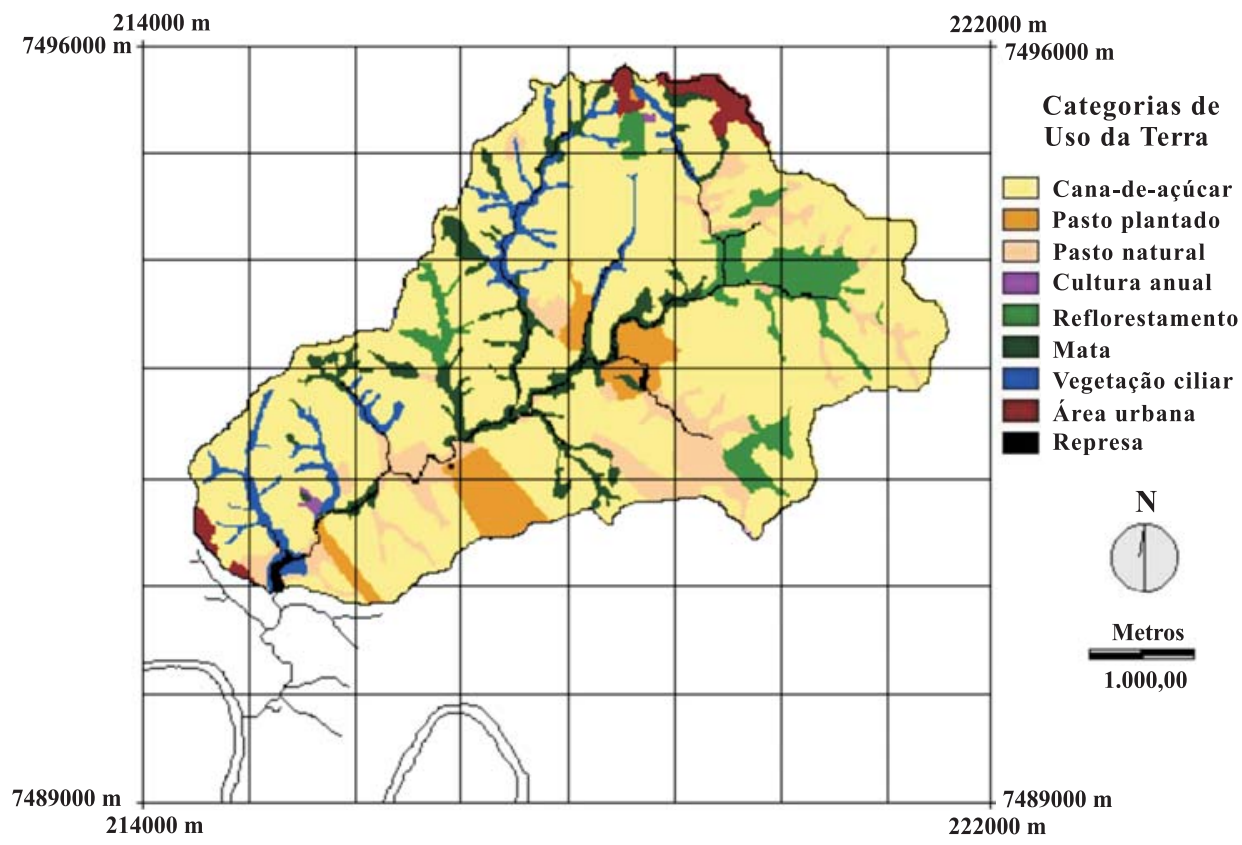

Figura 2. Mapa do uso das terras da área de estudo. Fonte: Fiorio (1998).

intrusivas básicas da Formação Serra Geral, ambos do Grupo São Bento, e por siltitos, argilitos e folhelhos da Formação Corumbataí, do Grupo Passa Dois (IPT, 1981). A formação Pirambóia recobre a formação Corumbataí, havendo locais em que banco silexítico típico da Formação Corumbataí marca o contato entre as duas formações.

De acordo com a carta pedológica semidetalhada elaborada por Oliveira et al. (1989), as principais classes de solos de ocorrência na área incluem Neossolos Litólicos distróficos fragmentários ou típicos A, moderados ou proeminentes; Neossolos Litólicos eutróficos chernossólicos fragmentários ou típicos, ambos substratos, sedimentos indiscriminados do Grupo Passa Dois, e Grupamento Indiscriminado de Argissolos Vermelho-Amarelos eutróficos ou distróficos abrúpticos A, moderados, textura arenosa/ argilosa ou média/argilosa, da Unidade Santa Cruz. Em menores proporções, nas áreas mais elevadas, ocorre Grupamento Indiscriminado de Argissolos VermelhoAmarelos eutróficos e distróficos abrúpticos A, moderados e espessos, textura arenosa/média, da Unidade Serrinha, associados ou não a Neossolos Litólicos eutróficos típicos ou chernossólicos, substrato arenito da Formação Pirambóia. Na região das cabeceiras de drenagem, associados aos afloramentos de instrusivas básicas, ocorrem Nitossolos Vermelhos eutroférricos chernossólicos ou típicos, da Unidade Santana, associados ou não a Neossolos Litólicos eutróficos típicos ou chernossólicos substrato basalto ou diabásio. A descrição dos solos encontra-se no trabalho de Oliveira (1999). A atualização da classificação dos solos foi realizada de acordo com o sistema brasileiro de classificação (Embrapa, 2006).

\section{Base cartográfica e implantação do banco de dados espaciais}

Os planos de informação relativos ao contorno da área, às curvas de nível $(\mathrm{DV}=5 \mathrm{~m})$ e à hidrografia foram extraídos de cartas topográficas (escala 1: 10.000) do Plano Cartográfico do Estado de São Paulo. A digitalização dos respectivos planos de informação foi realizada utilizando o programa gráfico AUTOCAD 12 (versão DOS), compatível com o programa IDRISI, utilizado nas versões for Windows e 32 (Eastman, 1993, 1999a, b).

Os arquivos digitais (formato .dxf) foram exportados para o programa IDRISI, um sistema de informação geográfica (SIG) do tipo matricial. Os arquivos vetoriais resultantes (.vct) foram convertidos no SIG para o formato matricial (.rst). A célula básica de informação ou pixel compreende uma área de 20 × 20 m nas direções X e Y. No georreferenciamento dos dados e informações, foi adotado o sistema de referência UTM $23 \mathrm{~S}$, datum $S A D$ 1969, meridiano central $45^{\circ}$ e elipsóide South American 1969.

\section{Plano amostral e georreferenciamento dos locais de amostragem}

Entre tradagens e trincheiras, o solo foi amostrado em 251 pontos na área de estudo (Figura 3), com prospecção e coleta de amostras até $120 \mathrm{~cm}$ de profundidade ou até o topo do horizonte C, CR ou R. O georreferenciamento dos pontos de amostragem foi realizado empregando a tecnologia de Sistema de Posicionamento Global (DGPS), com correção diferencial por pós-processamento, utilizando-se dois equipamentos manuais, modelo Geo Explorer II da Trimble. Um equipamento permaneceu estacionário, ligado a uma antena que funcionava como estação- 


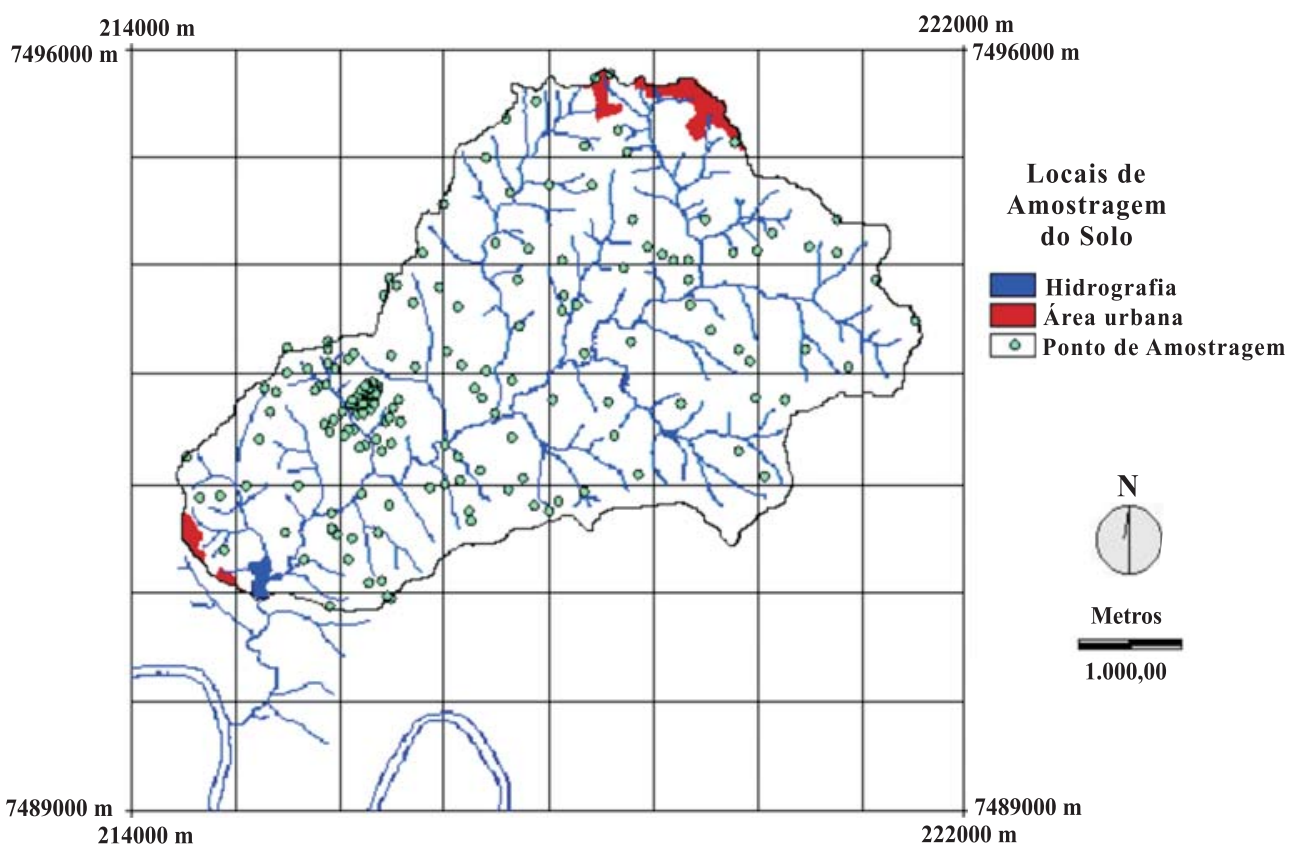

Figura 3. Locais de amostragem do solo na área de estudo.

base, e outro equipamento foi levado ao campo, para tomada das posições dos pontos de amostragem. A posição de campo foi corrigida em relação aos registros dos arquivos da estação base, utilizando o programa Pathfinder Office da Trimble.

\section{Métodos analíticos}

Foram efetuadas análises físicas e químicas das amostras de solo, visando a obtenção de dados para determinação da erodibilidade do solo, utilizando o método desenvolvido por Denardin (1990) para solos do Brasil e dos Estados Unidos. A análise granulométrica foi realizada no Laboratório de Física do Solo da ESALQ, empregando o Método de Boyoucos ou do Hidrômetro, conforme descrito em Kiehl (1979). As amostras de TFSA foram dispersas utilizando solução $0,1 \mathrm{~N}$ de $\mathrm{NaOH}$ e hexametafosfato de sódio e agitação lenta em agitador mecânico horizontal. A fração areia foi separada por tamisagem em cinco classes: areia muito grossa $(2,0-1,0 \mathrm{~mm})$; areia grossa $(1,0-0,5 \mathrm{~mm})$; areia média $(0,5-0,25 \mathrm{~mm})$; areia fina $(0,25-0,10 \mathrm{~mm})$; e areia muito fina $(0,10-0,05 \mathrm{~mm})$. A fração silte foi obtida por diferença. A matéria orgânica do solo foi determinada pelo método WalkleyBlack, conforme descrito em Raij et al. (1987). As análises foram realizadas no Laboratório de Química e Fertilidade do Solo da ESALQ.

\section{Equação universal de perda de solo (EUPS)}

A EUPS consiste de um modelo multiplicativo simples, pelo qual a perda média anual de solo, expressa em massa por unidade de área por tempo (A, em $\mathrm{Mg} \mathrm{ha}^{-1}$ ano $^{-1}$ ), é dada pelo produto de seis fatores determinantes, de acordo com a equação seguinte
(Wischmeier \& Smith, 1978; Bertoni \& Lombardi Neto, 1999):

$$
\mathrm{A}=\mathrm{R} * \mathrm{~K} * \mathrm{~L} * \mathrm{~S} * \mathrm{C} * \mathrm{P}
$$

sendo: $\mathrm{R}=$ fator erosividade da precipitação pluvial e da enxurrada, em MJ mm ha-1 $\mathrm{h}^{-1} \mathrm{ano}^{-1} ; \mathrm{K}=$ fator erodibilidade do solo, em $\mathrm{Mg} \mathrm{h} \mathrm{MJ}{ }^{-1} \mathrm{~mm}^{-1} ; \mathrm{L}=$ fator comprimento da encosta, adimensional; $\mathrm{S}=$ fator grau de declividade, adimensional; $\mathrm{C}=$ fator de cobertura $\mathrm{e}$ manejo da cultura, adimensional; e $\mathrm{P}=$ fator práticas de controle da erosão, adimensional.

Os fatores R, K, L e S dependem das condições naturais do clima, do solo e do relevo, e definem em conjunto o potencial natural de erosão. Os fatores $\mathrm{C} \mathrm{e}$ $\mathrm{P}$ são antrópicos e se relacionam com as formas de ocupação e uso das terras. Para aplicação do modelo em dada área, os referidos fatores devem ser ajustados considerando as condições locais.

A proposição de aplicar o modelo de erosão em uma plataforma digital de um sistema de informação geográfica, no caso do tipo raster ou matricial, exigiu planos de informação ou mapas de cada fator do modelo de erosão, que corresponde à representação espacial da sua variação na área de estudo.

A seguir, apresentam-se as funções e os procedimentos utilizados para ajuste local e espacialização dos fatores da EUPS.

\section{Fator $\mathbf{R}$ ou fator erosividade da precipitação pluvial e da enxurrada}

$\mathrm{O}$ fator $\mathrm{R}$ foi calculado a partir de índices mensais de erosão, obtidos pela equação (2), desenvolvida por Lombardi Neto \& Moldenhauer (1992):

$$
\mathrm{EI}_{\mathrm{i}}=67,355\left(\mathrm{r}_{\mathrm{i}}^{2} / \mathrm{P}_{\mathrm{i}}\right)^{0,85}
$$


sendo: $\mathrm{EI}_{\mathrm{i}}=$ média mensal do índice de erosão, no iésimo mês (MJ ha-1 $\mathrm{mm}^{-1}$ ); $\mathrm{r}_{i}=$ precipitação pluvial média mensal, em $\mathrm{mm}$, no iésimo mês; $\mathrm{P}_{i}=$ precipitação pluvial média anual, em $\mathrm{mm} ;(1 \leq \mathrm{i} \leq 12)$.

Como preconizado pelo método, no cálculo dos índices mensais de erosão $\left(\mathrm{EI}_{\mathrm{i}}\right)$ foi utilizada uma longa série de registros (80 anos) de precipitação pluviométrica, cedidos pelo Departamento de Ciências Exatas da ESALQ e provenientes do posto meteorológico da ESALQ/ USP.

O fator R, correspondente ao somatório dos índices mensais de erosão (Bertoni \& Lombardi Neto, 1999), foi considerado constante para toda a área de estudo. Para obtenção do mapa do fator $\mathrm{R}$, o valor calculado a partir da equação (2) foi atribuído a toda a área de estudo, por meio de operações simples de edit-assign efetuadas no SIG.

\section{Fator K ou fator erodibilidade do solo}

A erodibilidade dos solos da área de estudo (fator K) foi estimada para os 251 pontos amostrados e georreferenciados (Figura 3), empregando o modelo selecionado por Denardin (1990) para solos do Brasil e dos Estados Unidos, conforme equação (3) seguinte:

$$
\begin{gathered}
K=0,00000748 X_{1}+0,00448059 X_{2} \\
-0,0631175 X_{3}+0,01039567 X_{4}
\end{gathered}
$$

sendo: $\mathrm{K}=$ erodibilidade estimada, em $\mathrm{Mg} \mathrm{h} \mathrm{MJ}^{-1} \mathrm{~mm}^{-1}$; $\mathrm{X}_{1}=$ variável [("Novo" Silte + "Nova" Areia) * "Novo" Silte], sendo: "novo" silte $=$ silte + areia muito fina; "nova" areia = areia muito grossa + areia grossa + areia média + areia fina; $\mathrm{X}_{2}=$ variável permeabilidade do solo, de acordo com a classificação: (1) rápida; (2) moderada a rápida; (3) moderada; (4) lenta a moderada; (5) lenta; (6) muito lenta. $\mathrm{X}_{3}=$ variável diâmetro médio da partícula, ou DMP, expresso em $\mathrm{mm}$; calculado segundo a expressão:

$$
\mathrm{DMP}=\Sigma\left(\mathrm{C}_{\mathrm{i}} \mathrm{P}_{\mathrm{i}}\right)
$$

sendo: $\mathrm{C}_{\mathrm{i}}=$ centro da classe textural $\mathrm{i}$, expresso em mm; $\mathrm{P}_{\mathrm{i}}=$ proporção de ocorrência da classe textural i, expressa em \%; $\mathrm{X}_{4}=$ variável (MO \% * "Nova" Areia)/100, sendo MO \% o valor da matéria orgânica em percentagem.

As variáveis $\mathrm{X}_{1}, \mathrm{X}_{3}$ e $\mathrm{X}_{4}$ foram calculadas com base nos dados analíticos da camada de $0-20 \mathrm{~cm}$ dos solos. A variável $\mathrm{X}_{2}$ (classe de permeabilidade do solo) foi estimada analisando de forma integrada os dados de todo o perfil do solo, até o topo do horizonte $\mathrm{C}, \mathrm{CR}$ ou R. Nessa análise, efetuada para cada local amostrado, usando uma planilha eletrônica que reuniu todos os dados, foram considerados os seguintes atributos dos solos: profundidade do solum (A + B), ocorrência ou não de gradiente textural, granulometria, presença de mosqueados ou de cores de redução, uso da terra e posição na paisagem.

Para obtenção do mapa do fator K, foi levantada a hipótese inicial de que esse fator do modelo seria uma variável regionalizada, isto é, uma variável com dependência espacial, cuja variação no espaço não seria puramente aleatória, mas obedeceria a uma estrutura de variância. A dependência espacial pode ser verificada pela construção do semivariograma, a partir do cálculo das semivariâncias. Neste trabalho, o cálculo das semivariâncias foi realizado utilizando programa computacional desenvolvido pelo pesquisador Sidney Rosa Vieira, sendo ajustado aos dados um semivariograma do tipo exponencial (parâmetros $\mathrm{Co}=0,5 ; \mathrm{C} 1=0,65 ; \mathrm{a}=700 \mathrm{~m}$ ), comprovando a dependência espacial da erodibilidade do solo na área de estudo (Figura 4). Comprovada a hipótese de dependência espacial, é recomendado o uso de métodos geoestatísticos (Vieira et al., 1981, 1983), uma vez que a não-consideração da dependência espacial na análise dos dados pode afetar os resultados da pesquisa (Vieira, 1997).

A espacialização dos valores de erodibilidade foi efetuada por interpolação pelo método geoestatístico referido por krigeagem ordinária, utilizando os parâmetros do semivariograma. Este método de interpolação é considerado bom por não subestimar nem superestimar valores (sem viés) e porque os desvios em relação aos valores são mínimos (Vieira, 1997). A interpolação dos dados foi efetuada utilizando o já referido programa desenvolvido por Vieira. Os dados interpolados foram posteriormente exportados para o programa Surfer (Surfer Mapping System win 32, 1993-95; Golden Software Inc.). O arquivo gerado no Surfer (formato .gdr) foi então exportado para o IDRISI, para compor o mapa do fator K do modelo de erosão. A descrição detalhada dos procedimentos efetuados nesta etapa consta do trabalho de Weill (1999).

\section{Fator LS ou fator topográfico}

$\mathrm{Na}$ adaptação do modelo original, o fator $\mathrm{L}$, ou fator comprimento da encosta, e o fator $\mathrm{S}$, ou fator grau de declividade, foram combinados em um único fator, referido por fator LS ou topográfico, de acordo com a

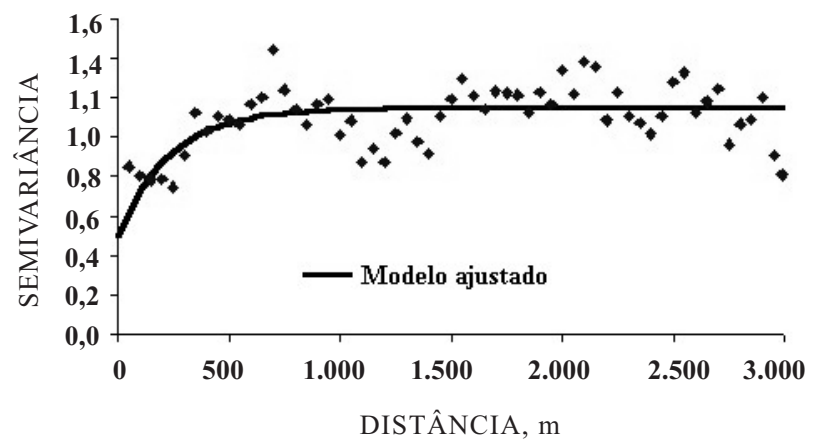

Figura 4. Semivariograma ajustado aos dados de erodibilidade do solo da área de estudo (modelo exponencial; parâmetros $C_{o}=0,5 ; C_{1}=0,65 ; a=700$ ). 
equação (5) desenvolvida por Bertoni \& Lombardi Neto (1999):

$$
\mathrm{LS}=0,00984 \mathrm{C}^{0,63} \mathrm{D}^{1,18}
$$

sendo: $\mathrm{LS}=$ fator topográfico (adimensional); $\mathrm{C}=\mathrm{com}-$ primento da vertente, em $\mathrm{m} ; \mathrm{D}=$ declividade, em $\%$.

Para o cálculo e espacialização do fator LS, mediante a aplicação da equação 5 , foram gerados no SIG os mapas de comprimentos das encostas (C, em metros) e de declividades ( $\mathrm{D}$, em porcentagem). Os mapas de declividades em graus e em porcentagem e o mapa de aspectos ou de orientação das vertentes em graus foram gerados diretamente a partir do modelo digital de elevação aplicando a função surface do IDRISI. O mapa de comprimento das encostas foi gerado no IDRISI de acordo com os procedimentos descritos por Rocha et al. (1995) e Ranieri (1996), com modificações efetuadas por Weill (1999), considerando duas situações distintas: áreas com cana-de-açúcar (terraceadas) e áreas com outros usos (nãoterraceadas), englobando matas, vegetação ciliar, reflorestamento, pastagens e a pequena fração com culturas anuais.

Nas áreas não-terraceadas, os mapas de aspecto e de declividade foram reclassificados em oito classes (função reclass) e, posteriormente, combinados em polígonos homogêneos (função crosstab), que foram então individualizados (função group). Foram gerados 6.220 polígonos dos quais foram extraídos os valores médios da declividade (em graus) e da amplitude da altitude (em $\mathrm{m}$ ), obtendo-se arquivos de valores (formato .txt). Exportados os dados para planilha eletrônica, a declividade média em graus foi convertida para radianos e calculados os valores dos senos. Os comprimentos das encostas $(\mathrm{L}, \mathrm{m})$ foram calculados por polígono utilizando a equação (6):

$$
\mathrm{L}=\mathrm{x} *(\operatorname{sen} \mu)^{-1}
$$

sendo: $\mathrm{L}=$ comprimento da encosta, em m (que se quer determinar); $\mathrm{x}=$ amplitude da altitude, em $\mathrm{m} ; \mu$ = ângulo de declividade, em graus.

Os valores de L obtidos foram então submetidos a funções lógicas para correção de distorções relacionadas com valores máximos possíveis em função do tamanho do polígono, comprimento de vertente tendendo a infinito em área com declividade média tendendo a zero, e comprimento de vertente igual a zero em área com amplitude de altitude igual a zero. $\mathrm{O}$ detalhamento das funções lógicas aplicadas consta do trabalho de Weill (1999). Ao final do processo, o arquivo contendo os valores de comprimento da encosta (formato .txt) foi exportado para o SIG, para geração do mapa de comprimentos de encostas das áreas ocupadas com outros usos.

Nas áreas com cana-de-açúcar, pelos mesmos processos descritos, foram individualizados 3.446 polígonos homogêneos quanto à classe de declividade e à classe de aspecto. Nessas áreas, os comprimentos das encostas foram calculados em função do espaçamento entre terraços, considerando uma distância vertical fixa de $5 \mathrm{~m}$ e o valor médio da classe de declividade (em graus). Também foram considerados os valores máximos recomendados de comprimento da encosta em função da classe de declividade, conforme definidos em Bertoni \& Lombardi Neto (1999). Os valores de comprimento da encosta (em metros) nas áreas terraceadas (uso com cana-de-açúcar) estão relacionados no quadro 1. Os dados obtidos foram exportados para planilha eletrônica para correção de distorções pela aplicação de funções lógicas, à semelhança do que foi feito para a área com outros usos. Posteriormente, os dados foram exportados para o SIG, para geração do mapa dos comprimentos das vertentes para as áreas de canade-açúcar.

\section{Fator $\mathrm{C}$ ou fator de cobertura e manejo da cultura}

O fator C expressa o efeito combinado da proteção oferecida pela cobertura vegetal e os diferentes sistemas de manejo. Os valores do fator $\mathrm{C}$ por categoria de uso da terra foram definidos a partir da literatura (Quadro 2). Para a cultura da cana-de-açúcar, os valores foram extraídos do trabalho de Machado et al. (1982). Para culturas anuais, o valor do fator C representa uma média dos valores apresentados no trabalho de Bertoni \& Lombardi Neto (1999). Para pastagens, naturais ou plantadas, o fator $\mathrm{C}$ foi extraído do trabalho de Menk (1993), e para reflorestamento, mata e vegetação ciliar os valores foram obtidos a partir do trabalho de Santos (1993). O mapa do fator C (cobertura e manejo da cultura) foi gerado no SIG utilizando as funções edit-assign do IDRISI, tomando por base os polígonos do mapa de uso da terra (Figura 2).

\section{Fator $\mathbf{P}$ ou fator prática de controle da erosão}

O mapa do fator P (práticas de controle da erosão) também foi obtido aplicando as funções edit-assign do IDRISI aos polígonos do mapa de uso da terra (Figura 2), sendo atribuído valor 0,5 às áreas

Quadro 1. Comprimento da encosta em metros por classe de declive para as áreas ocupadas com cana-de-açúcar na área de estudo

\begin{tabular}{cc}
\hline Classe de declive & Comprimento \\
\hline$\%$ & $\mathrm{~m}$ \\
$0-5$ & 140 \\
$5-10$ & 70 \\
$10-15$ & 40 \\
$15-20$ & 30 \\
$>20$ & 25 \\
\hline
\end{tabular}


Quadro 2. Fator C por categoria de uso da terra na área de estudo (Piracicaba, SP)

\begin{tabular}{ll}
\hline Uso da terra & Fator C \\
\hline Cana-de-açúcar & \\
Pastagens & $0,3066^{(1)}$ \\
Cultura Anual & $0,0080^{(2)}$ \\
Reflorestamento & $0,5500^{(3)}$ \\
Matas & $0,0010^{(4)}$ \\
Vegetação ciliar & $0,0001^{(4)}$ \\
\end{tabular}

(1) Estimado com base nos trabalhos de Machado et al. (1982) e Wischmeier \& Smith (1978). ${ }^{(2)}$ Extraído de Menk (1993). ${ }^{(3)}$ Adaptado de Bertoni \& Lombardi Neto (1999). ${ }^{(4)}$ Extraído de Santos (1993).

cultivadas com cana-de-açúcar (terraceadas) e valor 1,0 às áreas sem cana-de-açúcar (Bertoni \& Lombardi Neto, 1999).

\section{Estudo de sensibilidade dos fatores do modelo de erosão}

Cada fator da EUPS participou do modelo com o mesmo peso e com o mesmo grau de importância. A variação local dos fatores, no entanto, influenciou de maneira diferenciada a expectativa de erosão. $\mathrm{O}$ estudo de sensibilidade se restringiu aos fatores LS (topográfico), K (erodibilidade do solo), C (cobertura e manejo da cultura) e $\mathrm{P}$ (práticas de controle da erosão), uma vez que o fator $R$ (erosividade da chuva) foi mantido constante.

A influência dos fatores $\mathrm{C}$ e $\mathrm{P}$ foi avaliada empregando testes de médias das taxas estimadas de perda de solo pela EUPS por categoria de uso da terra, utilizando o programa estatístico SAS v.5 (SAS, 1991). A influência do fator $\mathrm{K}$ e do fator LS na variação das taxas de perda de solo estimadas foi analisada por categoria de uso e para a área de estudo como um todo, utilizando gráficos de dispersão gerados no SIG e simulações.

\section{RESULTADOS E DISCUSSÃO}

\section{Atributos dos solos da área de estudo de importância na caracterização da erodibilidade do solo ou fator $K$ da EUPS}

Os resultados das prospecções realizadas revelaram a ocorrência predominante de solos rasos ou pouco profundos, de acordo com as classes de profundidade definidas pela Embrapa (1988, 2006). Os solos mais espessos, com profundidade superior a $90 \mathrm{~cm}$, são comumente de textura média, mais permeáveis, ocorrendo predominantemente à margem direita do córrego do Ceveiro, como no caso dos Argissolos
Vermelho-Amarelos associados aos arenitos da Formação Pirambóia, do Grupo São Bento. Os solos da margem esquerda são em sua maioria rasos, com profundidades de até $50 \mathrm{~cm}$, como nos Neossolos Litólicos, ou pouco profundos, com profundidades entre 60 e 80 cm, caso de Cambissolos Háplicos identificados na área, possuem textura média ou argilosa, e são menos permeáveis em função da litologia constituída por siltitos, argilitos e folhelhos da Formação Corumbataí, do Grupo Passa Dois. A drenagem deficiente é sugerida pelos freqüentes mosqueados e cores de redução no solo, observados durante as amostragens. Particularmente, em relação aos Argissolos, é comum a mudança textural abrupta, conforme definida em Embrapa (1988, 2006). Caráter abrupto e de contato lítico são importantes fatores restritivos da permeabilidade e da capacidade de infiltração de água dos solos da área, aumentando a susceptibilidade à degradação pelo processo erosivo.

Quanto à granulometria, na camada de 0-20 cm, os teores de areia total variam na faixa entre $111 \mathrm{e}$ $940 \mathrm{~g} \mathrm{~kg}^{-1}$, os de silte entre 20 e $530 \mathrm{~g} \mathrm{~kg}^{-1}$, e os de argila entre 20 e $620 \mathrm{~g} \mathrm{~kg}^{-1}$, com médias de $611 \mathrm{~g} \mathrm{~kg}^{-1}$ $(\mathrm{CV}=38,5 \%), 187 \mathrm{~g} \mathrm{~kg}^{-1}(\mathrm{CV}=63.8 \%)$ e $202 \mathrm{~g} \mathrm{~kg}^{-1}$ $(\mathrm{CV}=65,2 \%)$, respectivamente. Na camada de 80$100 \mathrm{~cm}$, os teores de areia total variam na faixa entre 90 e $900 \mathrm{~g} \mathrm{~kg}^{-1}$, os de silte entre 20 e $400 \mathrm{~g} \mathrm{~kg}^{-1}$ e os de argila entre 40 e $700 \mathrm{~g} \mathrm{~kg}^{-1}$, com médias de $548 \mathrm{~g} \mathrm{~kg}^{-1}$ $(\mathrm{CV}=30,9 \%), 142 \mathrm{~g} \mathrm{~kg}^{-1}(\mathrm{CV}=54,6 \%)$ e $310 \mathrm{~g} \mathrm{~kg}^{-1}$ $(\mathrm{CV}=42,5 \%)$, respectivamente. $\mathrm{Na}$ fração areia predomina a subfração areia fina $(0,25$ a $0,10 \mathrm{~mm})$, seguida pela areia muito fina $(0,10$ a $0,05 \mathrm{~mm})$, sendo muito baixos os teores das outras três subfrações: areia média, areia grossa e areia muito grossa.

Com relação à matéria orgânica, os resultados obtidos mostram que os teores na camada de $0-20 \mathrm{~cm}$ são baixos a médios, na faixa entre 3 e $41 \mathrm{~g} \mathrm{~kg}^{-1}$, com média de $16 \mathrm{~g} \mathrm{~kg}^{-1}$, e desvio-padrão de $8,7 \mathrm{~g} \mathrm{~kg}^{-1}$. Valores acima de $50 \mathrm{~g} \mathrm{~kg}^{-1}$ são considerados altos, e valores abaixo de $16 \mathrm{~g} \mathrm{~kg}^{-1}$, baixos de acordo com a interpretação qualitativa de Tomé Jr. (1997). Em alguns locais da área de estudo, a combinação simultânea de baixos teores de matéria orgânica e de argila, ambos agentes cimentantes, com elevados teores de areia total, condiciona fraco desenvolvimento de estrutura e agregação da camada superficial do solo, favorecendo a erosão.

\section{Estimativa da erosão do solo na área de estudo (Piracicaba, SP)}

$\mathrm{O}$ fator $\mathrm{R}$ calculado para a área de estudo, de 6.273 $\mathrm{MJ} \mathrm{ha}^{-1} \mathrm{~mm}^{-1}$ ano $^{-1}$, representa um valor intermediário comparado àqueles calculados pelo mesmo método para o estado de São Paulo, entre 5.750 e $8.000 \mathrm{MJ} \mathrm{ha}^{-1} \mathrm{~mm}^{-1} \mathrm{ano}^{-1}$, conforme mapa de isoerodentes apresentado em Bertoni \& Lombardi Neto (1999). 
O mapa da erodibilidade do solo, ou Fator K (Figura 5), obtido a partir de métodos geoestatísticos, mostra que os menores valores estimados ocorrem mais próximos ao limite da área à margem direita do córrego do Ceveiro, variando entre 0,020 e $0,033 \mathrm{Mg} \mathrm{h} \mathrm{MJ}-1 \mathrm{~mm}^{-1}$. Nessa faixa de variação, enquadram-se cerca de $27 \%$ da área estudada (538 ha), onde predominam Argissolos Vermelho-Amarelos, de textura arenosa/média, seguidos por Neossolos Litólicos. Em cerca de $60 \%$ da área de estudo (1.208 ha), os valores de erodibilidade estimados são mais elevados e se situam entre 0,033 e $0,039 \mathrm{Mg} \mathrm{h} \mathrm{MJ}^{-1} \mathrm{~mm}^{-1}$, associados à ocorrência predominante de Neossolos Litólicos e de Argissolos Vermelho-Amarelos abrúpticos. Os maiores valores de erodibilidade, entre 0,039 e $0,048 \mathrm{Mg} \mathrm{h} \mathrm{MJ}^{-1} \mathrm{~mm}^{-1}$, ocorrem em cerca de $12 \%$ da área (244 ha), à margem esquerda do córrego do Ceveiro, associados a Neossolos Litólicos, Cambissolos Háplicos e Argissolos VermelhoAmarelos abrúptos. Os valores de erodibilidade estimados para a área de estudo situam-se na faixa de variação da erodibilidade para solos com horizonte B textural, entre 0,023 e 0,055 $\mathrm{Mg} \mathrm{h} \mathrm{MJ}^{-1} \mathrm{~mm}^{-1}$, conforme apresentado nos trabalhos de Lombardi Neto \& Bertoni (1975) e Bertoni \& Lombardi Neto (1999).

O mapa do fator LS (Figura 6) retrata uma grande amplitude de variação, com valores desde praticamente zero até o máximo de 9,877. Em 51,46\% da área (1.001,27 ha), o fator LS é igual ou inferior a 1,599 , podendo esse valor ser associado com comprimento de vertente em torno de $35 \mathrm{~m}$ (valor dentro da faixa de ocorrência mais freqüente) e declividade ao redor de $10 \%$. Por sua vez, o valor médio do fator LS, ponderado pela área, de 1,806 $(\mathrm{CV}=56,37 \%)$, pode ser associado com comprimento de vertente em torno de $60 \mathrm{~m}$, que corresponde ao comprimento médio da vertente na área de estudo, combinado com declividade também ao redor de $10 \%$.

A partir do ajuste dos fatores do modelo às condições locais, a aplicação da EUPS em ambiente SIG permitiu estimar e espacializar as taxas médias de perda de solo, basicamente associadas à erosão entressulcos e em sulcos pequenos (Wishmeier \& Smith, 1978), para as condições de uso e manejo da área de estudo (Figura 7). Como o modelo não contempla o fenômeno de deposição nas encostas, pode ter havido superestimativa de valores em certos locais, devendose interpretar as taxas estimadas como indicativos da expectativa da erosão e da intensidade local do processo.

Nas áreas ocupadas com usos menos intensivos, como mata, reflorestamento, vegetação ciliar e pastagens, as taxas estimadas são pequenas, sendo a perda média ponderada em relação à área de ocorrência por categoria de uso, de 2,0 $\mathrm{Mg} \mathrm{ha}^{-1} \mathrm{ano}^{-1}$. Em cerca de $50 \%$ da área com usos menos intensivos (314 ha), as perdas são inferiores a $0,44 \mathrm{Mg} \mathrm{ha}^{-1} \mathrm{ano}^{-1}$; em $90 \%$ (562 ha), a 5,0 Mg ha-1 ano $^{-1}$; e em $99 \%$ (624 ha), a 12,0 Mg ha-1 ano-1. Considerando a faixa de variação da tolerância média ponderada em relação à profundidade do solo, entre 4,5 e 13,4 $\mathrm{Mg} \mathrm{ha}^{-1}$ ano $^{-1}$ para solos com B textural, de acordo com Bertoni \& Lombardi Neto (1999), os valores estimados estão abaixo da tolerância, podendo-se inferir que as áreas com usos menos intensivos não se encontram sob processo de degradação do solo por erosão.

Nas áreas ocupadas com cana-de-açúcar, ao contrário, a expectativa média de perda de solo, ponderada em relação à área, corresponde a uma taxa de cerca de $58 \mathrm{Mg} \mathrm{ha}^{-1}$ ano $^{-1}(\mathrm{CV}=37 \%)$, valor quatro vezes maior do que o limite superior da tolerância

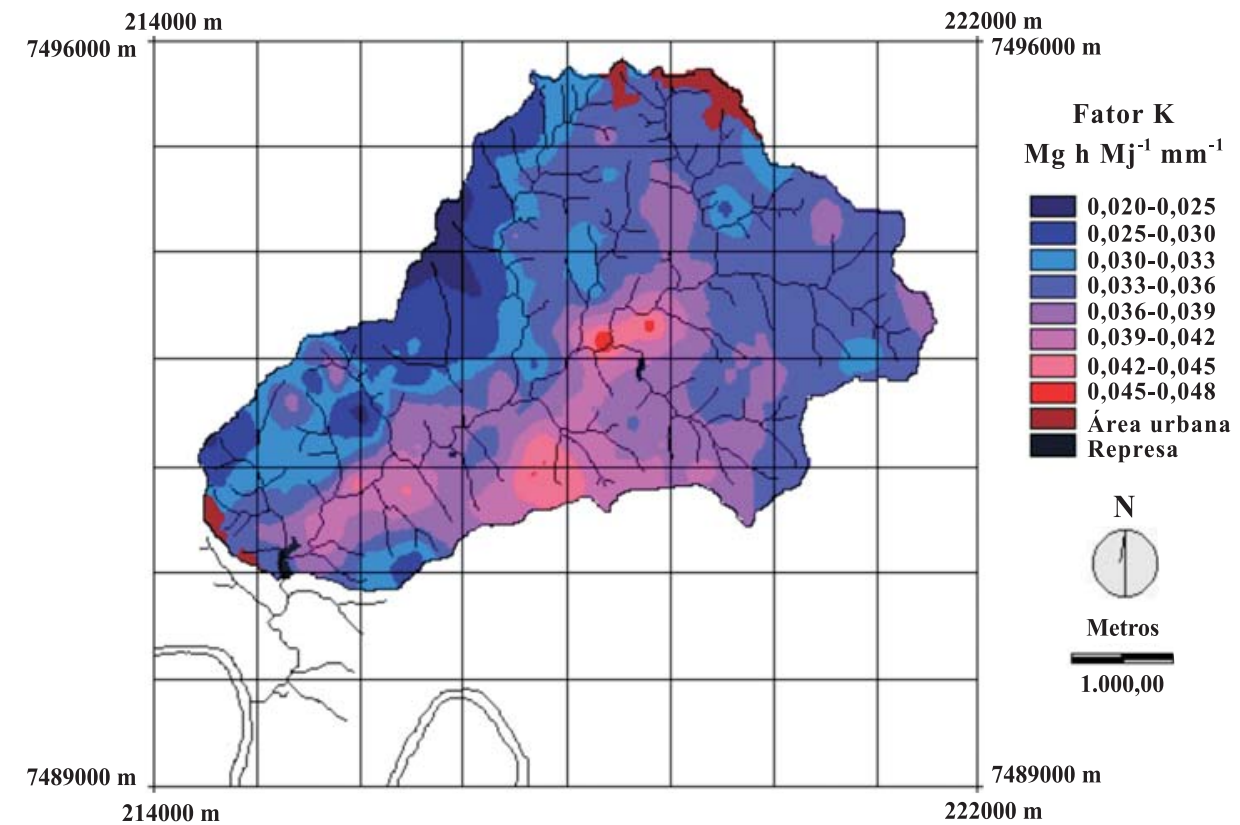

Figura 5. Mapa do fator K para a área de estudo. 


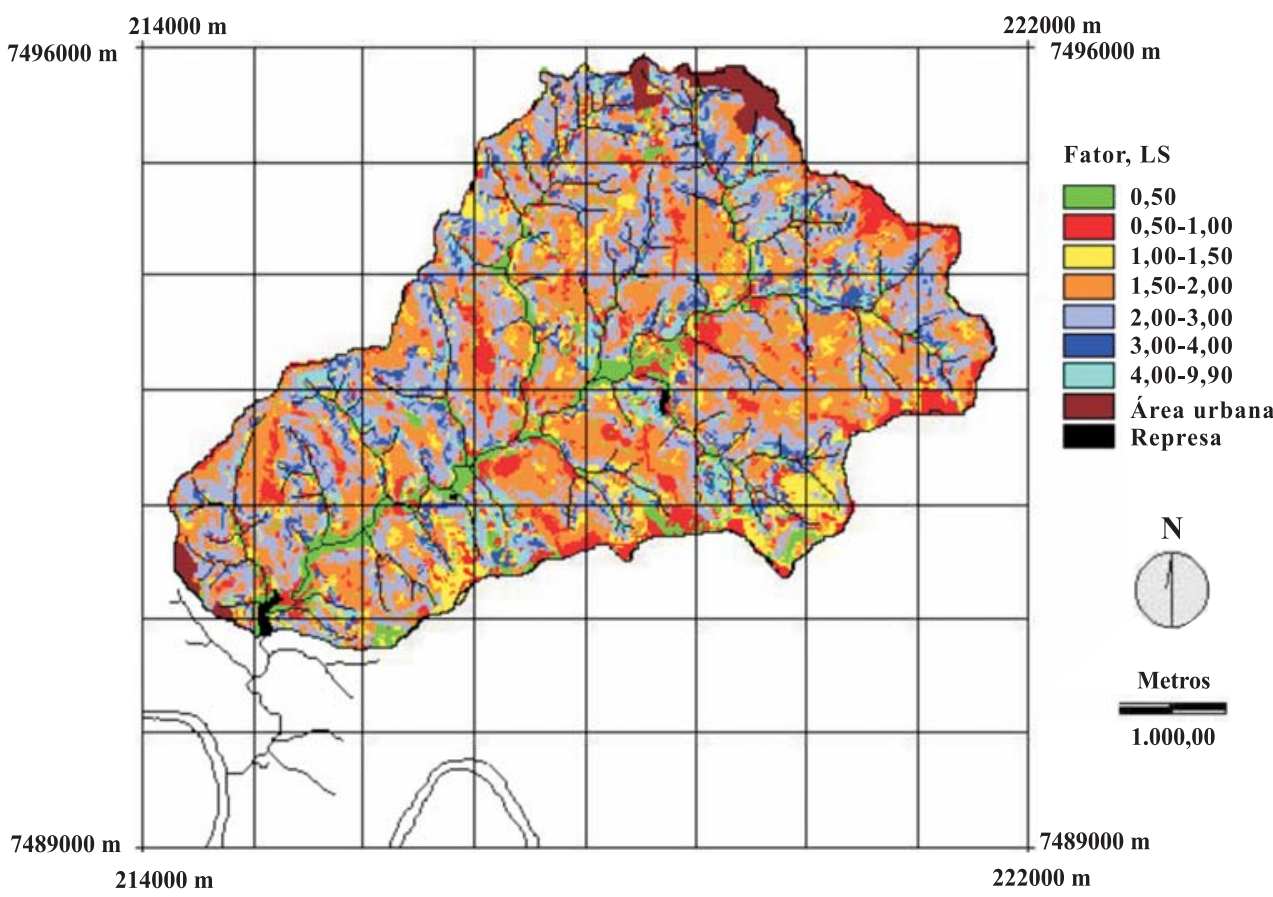

Figura 6. Mapa do fator LS para a área de estudo.

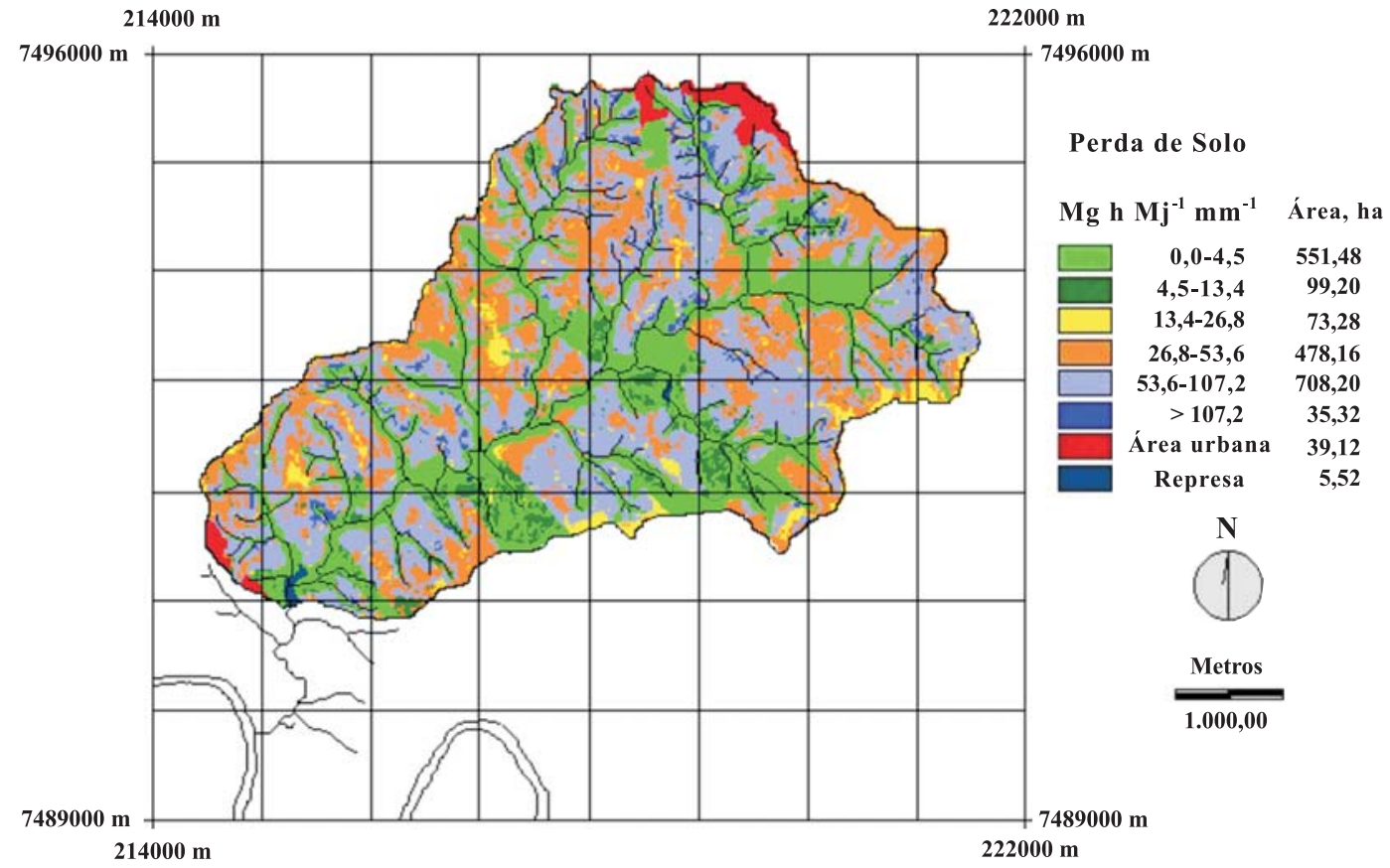

Figura 7. Estimativa da perda de solo (A, em $\mathrm{Mg} \mathrm{ha}^{-1} \mathrm{ano}^{-1}$ ) e ocorrência (área, em hectares) na área de estudo.

média de 13,4 $\mathrm{Mg} \mathrm{ha}^{-1}$ ano $^{-1}$. De fato, taxas de perda de solo abaixo do limite de tolerância ocorrem em apenas $2,0 \%$ da área ocupada com cana-de-açúcar (28,04 ha), podendo-se inferir, neste caso, que, na maior parte dessa área, a erosão é intensa e a degradação do solo acentuada.
$\mathrm{Na}$ área de estudo como um todo, as perdas de solo estimadas refletem uma situação intermediária, com taxa média de perda de solo, ponderada em relação à área total, de cerca de $39 \mathrm{Mg} \mathrm{ha}^{-1} \mathrm{ano}^{-1}$, e coeficiente de variação alto de $81 \%$. O histograma de freqüência das taxas de perda de solo na área de estudo (Figura 8) 
exibe duas concentrações de valores, em torno de 2,0 $\mathrm{Mg} \mathrm{ha}^{-1} \mathrm{ano}^{-1}$, taxa média de perda de solo nas áreas com uso menos intensivo, e em torno de $50,0 \mathrm{Mg} \mathrm{ha}^{-1} \mathrm{ano}^{-1}$, valor próximo à taxa média de perda de solo nas áreas ocupadas com cana-de-açúcar. O quadro 3 relaciona dados sobre as taxas estimadas de perda de solo e áreas acumuladas de ocorrência, podendo-se resumir que, para cerca de um terço da área de estudo, a expectativa de erosão está abaixo dos limites da tolerância média indicada para as classes de solos representadas, caracterizando baixa intensidade do processo erosivo, e nos dois terços restantes, associados ao uso com a cultura da canade-açúcar, a expectativa de erosão está acima daqueles limites, indicativo de intensidade moderada a alta do processo erosivo e degradação do solo instalada.

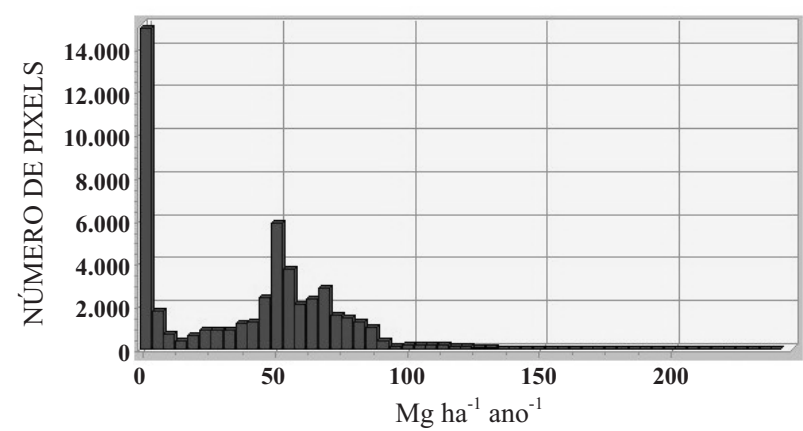

Figura 8. Histograma de freqüência das taxas médias de perda de solo estimadas pela EUPS (A, Mg ha ano $^{-1}$ ) na área de estudo.

Quadro 3. Perda de solo estimada (A, em Mg ha-1 ano ${ }^{-1}$ ) na área de estudo e áreas de ocorrência acumuladas

\begin{tabular}{ccc}
\hline $\begin{array}{c}\text { Taxa de perda de solo } \\
\text { na área de estudo }\end{array}$ & \multicolumn{1}{c}{ Ocorrência } \\
\hline $\mathrm{A}, \mathrm{em} \mathrm{Mg} \mathrm{ha}^{-1} \mathrm{ano}^{-1}$ & ha & $\%$ \\
$\leq 4,5$ & 551,48 & 28,34 \\
$\leq 13,4$ & 650,68 & 33,44 \\
$\leq 26,8$ & 723,96 & 37,21 \\
$\leq 53,6$ & 1202,12 & 61,79 \\
$\leq 107,2$ & 1910,32 & 98,18 \\
\hline
\end{tabular}

\section{Influência dos fatores da EUPS na variação das taxas estimadas de erosão do solo na área de estudo}

$\mathrm{Na}$ análise da influência dos fatores $\mathrm{C}$ e $\mathrm{P}$, os resultados dos testes de médias por categoria de uso da terra mostraram que a perda de solo média estimada nas áreas com cultura anual (menos de $1 \%$ da área de estudo), de $113,50 \mathrm{Mg} \mathrm{ha}^{-1} \mathrm{ano}^{-1}$, foi superior e significativamente diferente, a $5 \%$, pelo teste de
Tukey, da perda de solo estimada em todas as outras seis categorias de uso. A perda de solo média estimada para as áreas ocupadas com cana-de-açúcar (dois terços da área de estudo), no valor de $58 \mathrm{Mg} \mathrm{ha}^{-1} \mathrm{ano}^{-1}$, também foi significativamente diferente das perdas médias estimadas para todos os demais usos da terra, sendo superior em relação aos usos menos intensivos representados por mata e vegetação ciliar $\left(0,034 \mathrm{Mg} \mathrm{ha}^{-1} \mathrm{ano}^{-1}\right)$, reflorestamento $\left(0,46 \mathrm{Mg} \mathrm{ha}^{-1}\right.$ ano $^{-1}$ ) e pastagens $\left(3,50 \mathrm{Mg} \mathrm{ha}^{-1} \mathrm{ano}^{-1}\right)$, e inferior em relação ao uso mais intensivo, representado por cultura anual. As perdas de solo nas áreas utilizadas com pastagens superaram e foram significativamente diferentes das perdas estimadas nas áreas de mata, vegetação ciliar e reflorestamento. Não ocorreram diferenças significativas entre as perdas estimadas nas áreas de reflorestamento, mata e vegetação ciliar. Os resultados obtidos indicam que os fatores $\mathrm{C}$ e $\mathrm{P}$ determinaram a ordem de grandeza das perdas de solo na área de estudo em unidades, em dezenas ou em centenas de $\mathrm{Mg}$ ha $^{-1} \mathrm{ano}^{-1}$.

No estudo da influência do fator LS ou topográfico, a análise de dispersão das taxas de perda de solo (Figura 9a) discriminou quatro grupos de dados, designados por (1), (2), (3) e (4). É claramente perceptível, na figura 9a, que, a perda de solo dos grupos (1), (2) e (3) estava relacionada diretamente com o fator LS. Aparentemente para o grupo (4), este fator pouco influenciou as perdas estimadas do grupo (4), que se mantiveram muito baixas, praticamente nulas, em toda a faixa de variação do fator LS. A análise separada dos resultados, considerando a variação das taxas de perda de solo para cada categoria de uso em função da variação do fator LS, mostrou sempre uma relação direta e positiva, isto é, o aumento do fator LS promoveu aumentos proporcionais nas taxas estimadas de perda de solo para todos os grupos avaliados, inclusive para o (4). Observando conjuntamente esses resultados e aqueles obtidos dos testes de médias apresentados anteriormente, concluiu-se que os grupos (1) e (2), que detêm as taxas mais elevadas de perda de solo, representam as áreas ocupadas com cultura anual e com cana-de-açúcar, respectivamente, e que os dois outros grupos representam as ocorrências associadas às perdas de solo nas áreas ocupadas com pastagens (3) e com reflorestamento, mata e vegetação ciliar (4). Para os usos mais intensivos (grupos 1 e 2), a variação do fator LS promoveu uma ampla variação nas taxas estimadas de perda de solo, e o processo instalado foi intenso, considerando a inclinação das curvas.

Investigando o efeito do fator $\mathrm{K}$, a erodibilidade do solo, a dispersão dos dados sugere uma tendência de aumento das taxas de erosão em função do aumento da erodibilidade, mas, em contraste com o que foi observado em relação ao fator LS, a distribuição não mostra um padrão inequívoco (Figura 9b). Esse mesmo tipo de distribuição foi obtido quando se fez a dispersão considerando separadamente cada categoria de uso da terra. 

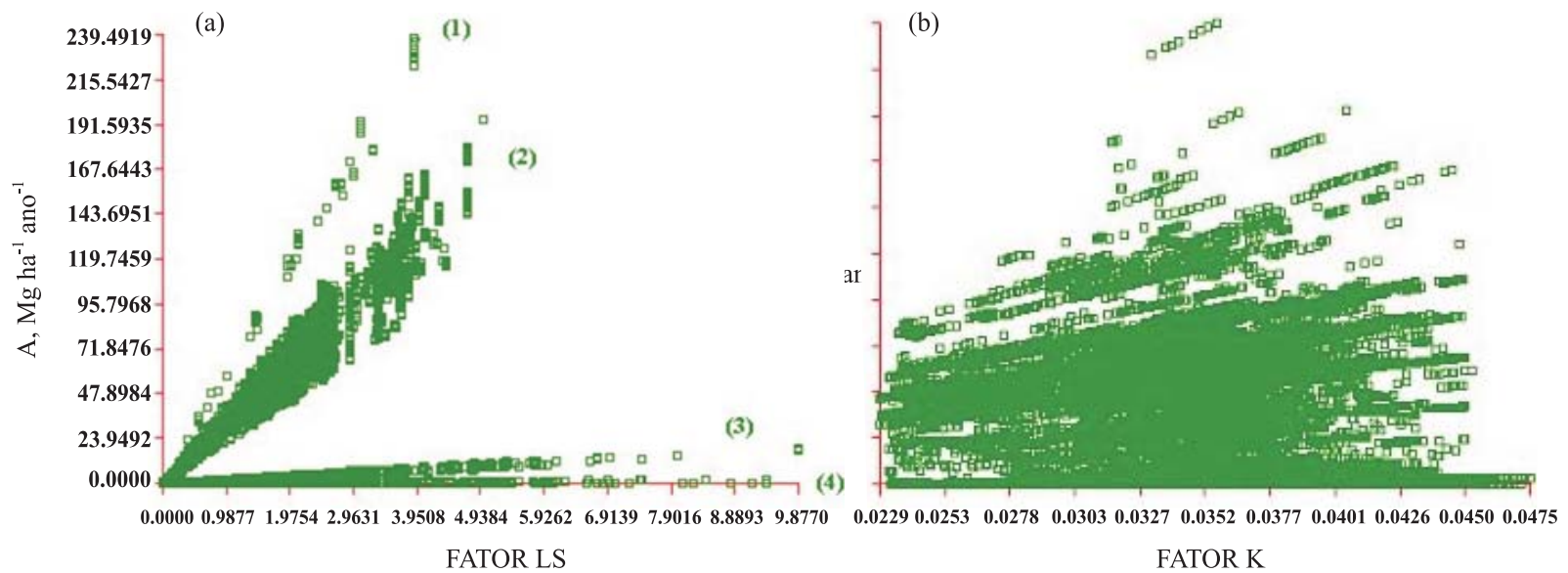

Figura 9. Dispersão da expectativa de perda de solo em relação à variação do fator LS (a) e do fator K (b), na área de estudo.

Nas áreas ocupadas com cana-de-açúcar, uma simulação mostrou que na faixa de variação do fator $\mathrm{K}$, mantidos constantes os demais fatores, as taxas de perda de solo dobraram quando se passou do menor valor de erodibilidade do solo $\left(0,020 \mathrm{Mg} \mathrm{h} \mathrm{MJ-1} \mathrm{mm}^{-1}\right)$ para o máximo valor $\left(0,051 \mathrm{Mg} \mathrm{h} \mathrm{MJ}^{-1} \mathrm{~mm}^{-1}\right)$, caracterizando a relação 1:2. Nas mesmas áreas, na faixa de variação do fator LS, mantidos constantes os demais fatores, obteve-se a elevada relação de 1:254, quando se passou do menor valor do fator LS (próximo de zero) para o valor máximo (de 9,88$)$. Os resultados evidenciam que o efeito do fator LS sobre as taxas de perda de solo foi muito mais acentuado em comparação com o efeito devido à variação da erodibilidade do solo ou fator K. Em termos operacionais e do ponto-devista econômico, os resultados obtidos foram promissores, pois, na caracterização do fator LS com uso de geotecnologias, o trabalho de campo foi muito menos intensivo, poupando tempo e recursos. E bastante recomendável, portanto, que mais esforços sejam dispensados para aperfeiçoamento de metodologias de obtenção das variáveis topográficas e do fator LS em ambiente de SIG. O trabalho de Valeriano (2002) é uma iniciativa nesse sentido.

\section{CONSIDERAÇÕES FINAIS}

A EUPS foi criada com o objetivo de estimar a perda média anual de solo decorrente da erosão em uma gleba homogênea, que se traduz por vertente reta, com grau de declividade uniforme e ângulo de orientação constante (Wischmeier \& Smith,1978). Aplicada em uma área em que a declividade não é uniforme e as vertentes não são necessariamente retas, decorrem limitações uma vez que o modelo não estima depósitos, nem a produção de sedimentos. No entanto, tendo em vista a simplicidade do modelo e a disponibilidade de funções para ajuste dos seus fatores às condições locais, em especial do estado de São Paulo, as taxas de perda de solo estimadas indicam a variação da intensidade do processo localmente, informação de grande valia no diagnóstico da erosão e no planejamento do uso das terras.

Considerando que pouco pode ser feito em relação ao potencial natural de erosão em dada área, o controle do processo comumente reside na adoção de alternativas adequadas e sustentáveis de uso e manejo das terras. No caso da área de estudo, foi caracterizada expectativa de erosão elevada nas áreas ocupadas com culturas, em especial com cana-de-açúcar, o uso predominante. As feições erosivas identificadas na área (Figura 10) e o assoreamento de represa nas proximidades do Distrito de Ártemis (Figura 11) sugerem que o processo erosivo instalado seja de fato intenso. Para serem validados os resultados obtidos, a partir de estudos complementares, alterações no manejo da cultura poderão incluir práticas para manutenção de maior cobertura sobre a superfície do solo, protegendo-o contra a erosão. Nas áreas de solos rasos, pouco permeáveis ou mais íngremes, o controle da erosão a níveis toleráveis poderá incluir até a retirada da cultura e usos menos intensivos com pastagens, reflorestamento ou mesmo recomposição da vegetação original.

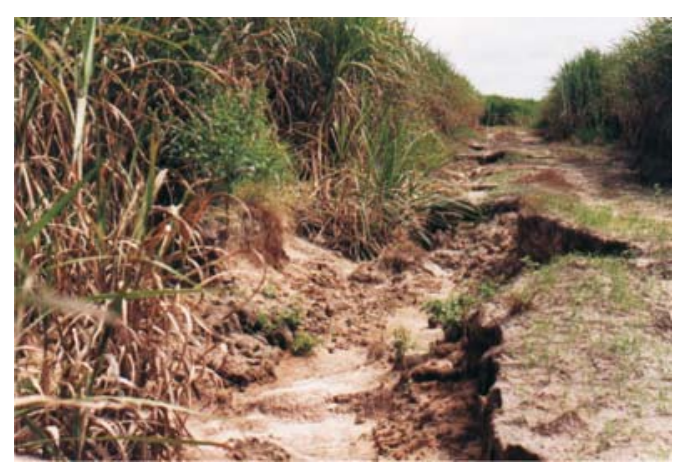

Figura 10. Feição erosiva na área, ocupada com canade-açúcar sobre Argissolo Vermelho-Amarelo distrófico abrúptico. 


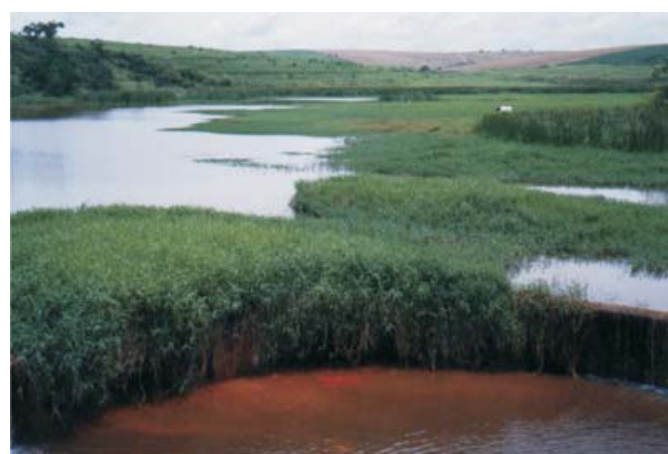

Figura 11. Aspecto de assoreamento em represa localizada na área de estudo (Piracicaba, SP), nas proximidades do Distrito de Ártemis.

\section{CONCLUSÕES}

1. A aplicação da equação universal de perda de solo com uso de geotecnologias permitiu estimar a expectativa de erosão na área de estudo, indicando a intensidade local do processo.

2. As maiores taxas de perda de solo foram estimadas para as áreas ocupadas com culturas, em especial com cana-de-açúcar, categoria de uso predominante.

3. Nas condições da pesquisa (fator $R$ constante), os fatores $\mathrm{C}$ (cobertura e manejo da cultura) e P (práticas de controle da erosão) definiram a ordem de grandeza das perdas estimadas pelo modelo. Para uma mesma categoria de uso da terra (fatores $\mathrm{C}$ e $\mathrm{P}$ constantes), o fator LS (topográfico) foi o que mais influenciou a variação observada nas taxas estimadas de erosão.

4. Estudos complementares são necessários para validação dos resultados obtidos, de modo a permitir recomendações específicas de uso e manejo para a área de estudo.

\section{AGRADECIMENTOS}

Á FAPESP, pela concessão de auxílio ao projeto de pesquisa. Ao Dr. Sidney Rosa Vieira, pesquisador do Centro de Solos e Recursos Agroambientais do Instituto Agronômico, pela colaboração no tratamento geoestatístico dos dados. Ao Dr. Álvaro Pires da Silva, professor do Departamento de Solos e Nutrição de Plantas da ESALQ/ USP, pela colaboração na execução das análises efetuadas com o programa SAS. À Dra. Isabella Clerici de Maria, pela colaboração na definição dos valores do fator $\mathrm{C}$ do modelo.

\section{LITERATURA CITADA}

BERTONI, J. \& LOMBARDI NETO, F. Conservação do solo. 4.ed. São Paulo, Ícone, 1999. 355p.
BOUMA, J. Using soil survey data for quantitative land evaluation. Adv. Soil Sci., 9:177-213, 1989.

CASTRO, O.M. Conservação do solo e qualidade dos sistemas produtivos. O Agronômico, 42:110-117, 1991.

DENARDIN, J.E. Erodibilidade do solo estimada por meio de parâmetros físicos e químicos. Piracicaba, Escola Superior de Agricultura Luiz de Queiroz, 1990. 114p. (Tese de Doutorado)

EASTMAN, J.R. Guide to GIS and image processing. IDRISI 32. Worcester, Clark University, 1999a. 193p. v.1.

EASTMAN, J.R. Guide to GIS and image processing. IDRISI 32. Worcester, Clark University, 1999b. 170p. v.2.

EASTMAN, J.R. IDRISI Manual. Worcester, Clark University, 1993.

EL-SWAIFE, S.A. \& DANGLER, E.W. Rainfall erosion in the tropics: A state-of-the-art. In: KUSSOW, W.; EL-SWAIFY, S.A. \& MANNERING, J., eds. Soil erosion and conservation in the tropics. Madison, American Society of Agronomy, 1982. p.1-25.

EMPRESA BRASILEIRA DE PESQUISA AGROPECUÁRIA EMBRAPA. Serviço Nacional de Levantamento e Conservação de Solo. Critérios para distinção de classes de solos e de fases de unidades de mapeamento; normas em uso pelo SNLCS. Rio de Janeiro, 1988. 67p. (Documentos, 11)

EMPRESA BRASILEIRA DE PESQUISA AGROPECUÁRIA EMBRAPA. Sistema brasileiro de classificação de solos 2.ed. Rio de Janeiro, Centro Nacional de Pesquisa de Solos, 2006. 306p.

FIORIO, P.R. Avaliação cronológica do uso da terra e seu impacto no ambiente da microbacia hidrográfica do córrego do ceveiro da região de Piracicaba, SP. Piracicaba, Escola Superior de Agricultura Luiz de Queiroz, 1998. 114p. (Tese de Mestrado)

INSTITUTO DE PESQUISAS TECNOLÓGICAS - IPT. Mapa geológico do Estado de São Paulo. Escala 1:500.000. São Paulo, 1981. 2v. escala 1: 500.000 (Monografias, 6)

KIEHL, E.J. Manual de edafologia: relações solo-planta. São Paulo, Ceres, 1979. 262p.

LAL, R. Soil erosion by wind and water: Problems and prospects. In: LAL, R., ed. Soil erosion research methods. Delray Beach, St. Lucie Press, Soil and Water Conservation Society, 1994. p.1-9.

LAL, R. \& STEWART, B.A. Soil degradation: A global threat. Adv. Soil Sci., 11:13-17, 1990.

LOMBARDI NETO, F. \& BERTONI, J. Erodibilidade de solos paulistas. Campinas, Instituto Agronômico de Campinas, 1975. 12p. (Boletim Técnico, 27)

LOMBARDI NETO, F. \& MOLDENHAUER, W.C. Erosividade da chuva: sua distribuição e relação com as perdas de solo em Campinas (SP). Bragantia, 51:189-196, 1992.

MACHADO, E.C.; PEREIRA, A.R.; FAHL, J.I.; ARRUDA, H.V. \& CIONE, J. Índices biométricos de duas variedades de cana-de-açúcar. Pesq. Agropec. Bras., 17:1323-1329, 1982. 
MARQUES, J.Q. A política de conservação do solo. Rio de Janeiro, Ministério da Agricultura, 1949. 73p. (Boletim do Serviço de Informação Agrícola, 734)

Mc COOL, D.K. \& RENARD, K.G. Water erosion and water quality. Adv. Soil Sci., 13:175-185, 1990.

MENK, P.C.M. Avaliação econômica do controle da erosão na microbacia do Ribeirão Iperó, em Araçoiaba da Serra, Estado de São Paulo. Piracicaba, Escola Superior de Agricultura "Luiz de Queiroz", 1993. 181p. (Tese de Mestrado)

OLIVEIRA, J.B. Solos da Folha de Piracicaba. Campinas, Instituto Agronômico, 1999. 173p. Contém carta pedológica semidetalhada, escala 1:100.000. (Boletim Científico, 48)

OLIVEIRA, J.B.; PRADO, H.; BEJAR, O.I.G.; OLIVEIRA, E.R.; NOGOBARDI, R.C. \& ASSIS, E.A. Carta Pedológica Semidetalhada do Estado de São Paulo: Piracicaba. São Paulo, Secretaria de Agricultura/CPA/IA; Secretaria da Economia e Planejamento/CAR/IGC, 1989. (Mapa escala $1: 100.000)$

RAIJ, B. van; QUAGGIO, J.A., CANTARELLA, H.; FERREIRA, M.E.; LOPES, A.S. \& BATAGLIA, O.C. Análise química de solos para fins de fertilidade. Campinas, Fundação Cargill, 1987. 170p.

RANIERI, S.B.L. Avaliação de métodos e escalas de trabalho para determinação de risco de erosão em bacia hidrográfica utilizando SIG. São Carlos, Escola de Engenharia de São Carlos, 1996. 128p. (Tese de Mestrado)

ROCHA, J.V.; LOMBARDI NETO, F. \& BACELLAR, A.A.A. Cálculo do fator comprimento de rampa (L): uma metodologia para uso em Sistema de Informação Geográfica. In: SIMPÓSIO NACIONAL DE CONTROLE DE EROSÃO, Bauru, 1995. Resumos. Bauru, 1995. p.421422 .
ROSE, C.W. Modeling erosion by water and wind. In: LAL, R.; BLUM, W.H.; VALENTINE, C. \& STEWART, B.A. Methods for assessment of soil degradation. New York, CRC Press, 1997. p.57-88. (Advances in Soil Science)

SANTOS, M.F. Subsídios para o planejamento conservacionista da bacia hidrográfica do Ribeirão do Feijão (São Carlos, Itirapina e Analândia, SP). São Carlos, Escola de Engenharia de São Carlos, 1993. 222p. (Tese de Mestrado)

SAS Institute. Statistical Analysis System Institute. SAS/ STAT procedure guide for personal computers. v.5. Cary, 1991.

SCHERTZ, D.L. The basis for soil loss tolerances. J. Soil Water Conserv., 38:10-14, 1983.

TOMÉ JR., J.B. Manual para interpretação de análise de solo. Guaíba, Agropecuária, 1997. 247p.

VALERIANO, M.M. Mapeamento do comprimento de rampa em microbacias com sistemas de informação geográfica. Acta Sci., 24:1541-1551, 2002.

VIEIRA, S.R. Variabilidade espacial de argila, silte e atributos químicos em uma parcela experimental de um Latossolo Roxo de Campinas (SP). Bragantia, 56:181-190, 1997.

VIEIRA, S.R.; HATFIELD, J.L.; NIELSEN, D.R. \& BIGGAR, J.W. Geostatistical theory and application to variability of some agronomical properties. Hilgardia, 51:1-75, 1983.

VIEIRA, S.R.; NIELSEN, D.R. \& BIGGAR, J.W. Spatial variability of field-measured infiltration rate. Soil Sci. Soc. Am. J., 45:1040-1048, 1981.

WEILL, M.A.M. Estimativa da erosão do solo e avaliação do seu impacto na microbacia do Ceveiro (Piracicaba, SP), através do Índice de Tempo de Vida. Piracicaba, Escola Superior de Agricultura Luiz de Queiroz,1999. 100p. (Tese de Doutorado)

WISCHMEIER, W.H. \& SMITH, D.D. Predicting rainfall erosion losses: A guide to conservation planning. Washington, USDA, 1978. 57p. (Agricultural Handbook, 537) 